\title{
Health economics made easy: guiding the initiated and uninitiated
}

\author{
CHARLES NORMAND* \\ Edward Kennedy Professor of Health Policy and Management, Trinity College Dublin, Ireland
}

\author{
Applied Health Economics \\ Andrew M Jones, Nigel Rice, Teresa Bago d'Uva and Silvia Balia \\ Abingdon: Routledge, 2007
}

\section{Health Care Economics}

Thomas E Getzen with Bruce H Allen

Chichester: Wiley, 2007

For many years it was a challenge in teaching health economics to find a textbook that exactly fits the needs of a class, not least because the needs of student are so diverse. To an extent, this remains the case despite the appearance of several new and useful contributions in the last few years. At times it seemed like cable television - lots of choices, but nothing that is quite what you want. Cullis and West (1979) worked well for many groups, but was allowed to get out of date, and went out of print for several years. McGuire et al. (1988) was a good option for people with a background in economics, and provided a comprehensive treatment of the subject, but generated antibodies in the student new to the subject. Gavin Mooney (1992) targeted several books to the interested lay reader, but these lacked the rigour needed for the more serious student. Before going further, I must declare an interest since the second edition of the textbook by Barbara McPake and me (2008) has recently been published. It competes directly with some of the other texts discussed below, but for obvious reasons is not reviewed.

A difficulty facing authors of textbooks in health economics is the (at least perceived) difference in the appropriate applications of economics to health care depending on the health system involved. In some ways this makes no sense, since economic principles are universal, and the choices and dilemmas differ more in degree than in type, but as with any social science, the development of ideas and approaches depends on the main issues that are perceived

*Correspondence to: Charles Normand, Edward Kennedy Professor of Health Policy \& Management, University of Dublin, Trinity College, 3-4 Foster Place, Dublin 2, Ireland. Email: normandc@tcd.ie 
in the policy debate. US books tend to focus on issues of insurance and reimbursement systems, and to some extent regulation of health care providers issues that feature less in countries with universal access to most health services through social insurance or tax-based finance. In Europe the agenda was more focused on economic evaluation and setting priorities, and courses in health economics tended to be centred on these uses of economics. Public or quasi-public health care agencies were more directly aware of their role in managing rationing of services, and were (sometimes) keen to base such rationing on rigorous and scientific analysis.

Despite a somewhat American focus, texts such as Folland et al. (2007) and Getzen's earlier book (1997) have been popular in other countries. Getzen is more accessible, but does not offer as rigorous a treatment of the more technical issues. Until fairly recently there was no good European text aimed at the interested amateur, although this gap has been filled recently by a number of new contributions such as Philips (2005) and Wonderling et al. (2005). Wonderling et al. is specifically aimed at the student studying in a distance-learning context, and is at its best when the full array of resources is available to the student. It also covers only some parts of the subject, with companion volumes covering economic evaluation and management and policy. Morris et al. (2007) offers a good new and comprehensive text, somewhat less accessible than Wonderling, but with much greater scope.

Economic evaluation texts and guides have had two purposes - to provide guidance on how to carry out the analysis, and to specify best (or at least good) practice. For many years this field was dominated by Gold et al. (1996) and the various editions of Drummond et al. (2005). The faint hearted preferred to start with Jefferson et al. (2005). The techniques in economic evaluation have been developing quickly, and there are now available several books that deal with specific features (e.g. Briggs et al., 2006, Brazier et al., 2007). As economic evaluation comes to be applied widely in the assessment of new health technologies, and indeed in decisions on what is and what is not included in available packages of care, there has been great interest in specifying the appropriate evaluation procedures. Economists have instinctively rejected such an approach, being since J. S. Mill suspicious of professions and experts, and the history of the guidance reflects both what was intellectually rigorous and what was feasible.

Interest has grown in many countries in the mechanisms for financing services. Donaldson et al. (2005) and the earlier edition have been the market leader in this area. Several books focus on the issues specific to developing countries such as Witter et al. (2000), but sadly many of these have tended to be allowed to get out of date. The growing interest in applying econometric techniques has been reflected in the earlier work by Jones (2007). For those strong enough to carry it, a more comprehensive guide to health economics is available in Culyer and Newhouse (2000). 
Against this background, the author of a new book on health economics must have something special to offer. These two recent textbooks aim to fill gaps at different ends of the market, the skilled user of economic ideas (especially those with an econometric bent) and the interested newcomer. However, they have one thing in common - they both aim to remove the mystery from the use of economic ideas in health. Jones et al. aim to guide the reader to make use of the best available econometric techniques to analyse health issues. The guidance offered is very detailed and includes examples of the appropriate STATA code. Getzen aims to provide an accessible introduction to the subject, aimed mainly at those who want some understanding but are not planning to work as economists. In many ways it covers similar ground to his previous best-selling textbook, but, as in the case of Jones et al., the book marks a departure from the conventional textbook style, and provides resources beyond what is normal.

The Wiley Pathway texts aim to be more than a textbook, providing broader learning resources, with supporting exercises and assessment to support selfdirected learning. The student is able to assess his or her level of understanding at the end of each section, and the whole package provides enough support to make self-directed learning possible. Getzen defines terms clearly, and his explanations demonstrate his skills as a teacher. The book is aimed at the student who is new to economic ideas, and to some extent the issues and ideas have to be simplified, but the book includes effective use of real-life examples. The tone and clarity of expression reflect Getzen's wide knowledge of the subject and experience working in the field. The style is quite conversational, and the whole experience of reading it is pleasant, although the reader does not feel patronized. The qualities in his earlier book that made it popular with students over the years will make this book popular as well.

Getzen locates his analysis in experiences from around the world, and draws examples from many continents. However, this book is at its best as an US book for US students, and readers from other countries may be puzzled by the emphasis given to some topics. This is not to argue that there is no relevance of the US experience to other countries. There is of course some merit in the argument that the way to learn from the US health care system is to study it carefully and do precisely the opposite, but in reality there is much more to learn. In many senses, the US provides a clear lens with which to see universal issues the particular mix of private and public funding and provision makes the generic dilemmas and choices more visible. In most other developed countries there is little real debate about mechanisms for financing health care, and the private insurance component of funding is relatively small. Similarly, in many developed countries doctors are paid salaries or on a basis that limits their income, and some cost control issues are less serious. The student from outside the US will find the coverage of general economic principles very clear, and will learn a lot about the mechanisms in the US health care system. The careful reader will also be able to find useful insights applicable to other systems, but more 
help would be needed to make this book useful to clinical and management readers across the World. It is likely that this book will become the standard text for managers and health professionals in the US who wish to understand the economic environment in which they work.

As suggested above, the book by Jones et al. also aims to demystify, but in this case the target is the advanced student or researcher who wishes to use the best econometric techniques to analyse health issues. It is a puzzle why the term applied economics has come to be applied to econometric work, and this is the usage in this case. At first glance this book seems almost too helpful - the reader is guided through the economic and statistical arguments, and is also provided with a user guide to STATA programming. There is the obvious risk that it is used as health econometric painting by numbers, and could be abused by people with limited understanding of what they are doing. That said, the serious user will be provided with a very useful guide to actually carrying out analysis, and should have the satisfaction of getting the programmes to work. Reading through the book it is clear that an attempt has been made to minimize the use of confusing terminology, and to enlighten rather than confuse. However, as is so often the case with work by very competent technicians, there are some gaps where the reader is assumed to understand the concepts that are not completely intuitive.

The framework for this book is a set of existing, published studies on topics such as self-reported health, smoking, and mortality, and health and retirement, and these are used to illustrate approaches to analysis of categorical data and panel data. What the book does is to demonstrate how the studies were carried out in much more detail than is possible in the reports in journal articles. This is somewhat analogous to the second CDs that are now sold along with many Disney films, showing how the film was made and what bits were left out of the final product. The book provides insight into what choices were made, what analysis done, what approaches were discarded, and how the final paper was crafted. It shows the choice of statistical techniques and the necessary code to run the analysis. While in some senses what is provided duplicates material already in the public domain, as a learning resource this approach is very useful. Students are often frustrated by the difficulty in working back from the limited detail in peer-reviewed papers about what was actually done and how it was done.

Health econometrics is a rapidly evolving field. This book will inevitably go out of date quite quickly as the techniques evolve and the programmes become more powerful and easier to use. As things stand the studies described here are still near the cutting edge, and the guidance on methods and techniques is as good as can be found. In the longer run, it is likely that material of this sort will be published in softer forms, and will allow more frequent and continuous revision. In places the text reads a little like an interactive learning resource. 
Both these books are likely to find a successful niche, although of the two Getzen's will fund more holidays. In some respects the greatest interest is in the way in which they both depart from current practice, and may signify the way that text books are moving - from passive resource for the energetic student to a fuller learning resource that provides both content and support to the process. In some ways both could equally have appeared as CD-ROMs, and it is likely that in the long run softer formats will displace books of this sort. In the meantime these two books may go some way to increasing the economic literacy of clinicians and managers, and may provide some quality assurance in the use of econometric techniques. The authors are also making rods for their backs - in both cases the books will require frequent updating to retain their positions.

\section{References}

Brazier, J., J. Ratcliffe, J. Salomon, and A. Tsuchiya (2007), Measuring and Valuing Health Benefits for Economic Evaluation, Oxford: Oxford University Press.

Briggs, A., K. Claxton, and M. Sculpher (2006), Decision Modelling for Health Economic Evaluation, Oxford: Oxford University Press.

Cullis, J. and P. West (1979), The Economics of Health, Oxford: Martin Robertson.

Culyer, A. and J. Newhouse (eds) (2000), Handbook of Health Economics, Amsterdam: Elsevier North-Holland.

Donaldson, C., K. Gerard, C. Mitton, S. Jan, and V. Wiseman (2005), Economics of Health Care Financing: The Visible Hand, London: Palgrave Macmillan.

Drummond, M., M. Sculpher, G. Torrance, B. O'Brien, and G. Stoddart (2005), Methods for the Economic Evaluation of Health Care Programmes, Oxford: Oxford University Press.

Folland, S., A. Goodman, and M. Stano (2007), The Economics of Health and Health Care, 5th edn, Glenview Il: Prentice Hall.

Getzen, T. (1997), Health Economics: Fundamentals and Flow of Funds, New York: John Wiley \& Sons.

Gold, M., J. Seigel, L. Russel, and M. Weinstein (1996), Cost-effectiveness in Health and Medicine, New York: Oxford University Press.

Jefferson, T., V. Demicheli, and M. Mugford (2000), Elementary Economic Evaluation in Health Care, London: BMJ Publishing.

Jones, A. (2007), Applied Econometrics for Health Economists: A Practical Guide, 2nd edn, Oxford: Radcliffe Medical Publishing.

McGuire, A., J. Henderson, and G. Mooney (1988), The Economics of Health Care, London: Routledge \& Kegan Paul.

McPake, B. and C. Normand (2008), Health Economics: An International Perspective, 2nd edn, London and New York: Routledge.

Mooney, G. (1992), Economics, Medicine, and Health Care, Hemel Hempstead: Harvester Wheatsheaf. 
Morris, S., N. Devlin, and D. Parkin (2007), Economic Analysis in Health Care, Chichester: John Wiley \& Sons.

Phillips, C. (2005), Health Economics: An Introduction for Health Professionals, Oxford: Blackwell.

Witter, S., T. Ensor, M. Jowett, and R. Thompson (2000), Health Economics for Developing Countries: A Practical Guide, London: Macmillan Education.

Wonderling, D., R. Gruen, and N. Black (2005), Introduction to Health Economics, Maidenhead: Open University Press. 